\section{E-LOGOS}

ELECTRONIC JOURNAL FOR PHILOSOPHY ISSN 1211-0442

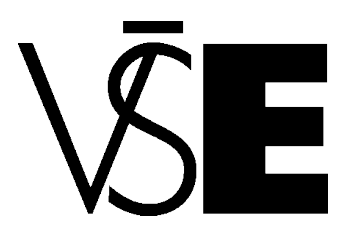

University of Economics

Prague

\title{
The Dualism of Conceptual Scheme and Undifferentiated Reality
}

Terence Rajivan Edward

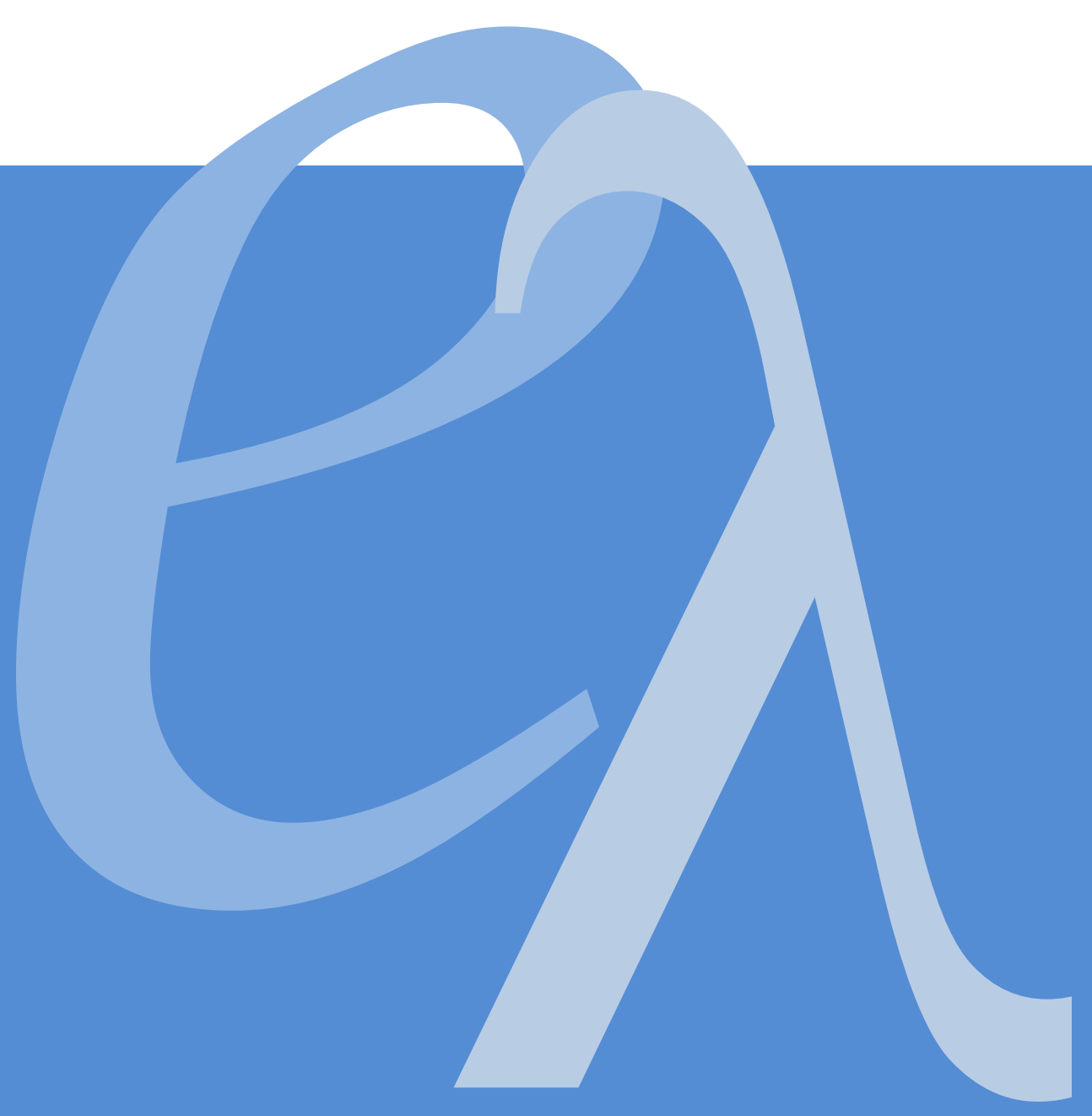




\begin{abstract}
This paper evaluates a form of dualism, which is referred to here as the dualism of conceptual scheme and undifferentiated reality. According to this dualism, although reality appears to be divided into distinct things from the perspective of our system of concepts, it is actually not. I justify the view that this dualism is incoherent.
\end{abstract}


1. This paper objects to a form of dualism. We encounter this form of dualism in the claim that different conceptual schemes divide up an undifferentiated reality in different ways. On the one hand, there are conceptual schemes. On the other hand, there is the undifferentiated reality that gets divided up. Philosophers sometimes count this dualism as a version of the dualism of scheme and content (Davidson 1984: 192; Rorty 1998: 90). However, the term 'the dualism of scheme and content' is also used in such a way that it does not refer to this dualism at all (e.g., McDowell 1999). In order to avoid confusion, the form of dualism which is evaluated here will be referred to as the dualism of conceptual scheme and undifferentiated reality. I first introduce this dualism for any readers unfamiliar with it. I then present an objection which establishes that, although it might look coherent to begin with, on closer inspection it is not.

2. One attempt to conceive of an undifferentiated reality is to think of reality as a physical object which is not composed of any smaller physical objects. Wherever we would say that one physical object is ending and another is beginning, there is just the continuation of a single physical object, reality. For example, if there is a rock and a coin under the rock, we ordinarily think that at some points the rock ends and the coin begins. But actually there is not the rock, as one object, and the coin, as something else. It is all one thing. The explanation just given, however, does not capture how reality being undifferentiated will be understood in this paper.

If reality is undifferentiated, then whenever we attempt to refer to two distinct things within reality, A and B, it is not the case that there actually are two distinct things, 'distinct' here meaning non-identical. This is so regardless of what A and B are: whether the terms for them aim to pick out objects, properties or any other kind of thing. For reality to be undifferentiated is for it to not feature distinct things, so there cannot be accurate representations of this kind. One of the differences between this explanation and the previous one is that it goes beyond a focus purely on objects. The previous explanation makes it seem as if there are distinct properties of reality, such as it being spatially extended and it being subject to change. There is nothing about these properties which means they are beyond accurate conceptual representation. But the kind of dualist we are considering typically wants to treat conceptual representations which posit these properties as capturing how reality appears from the point of view of our scheme, not how it actually is. Consider these claims by William Child about the commitments of this dualist:

Here, the idea is that the world is completely unstructured; a bare something, a mass of undifferentiated stuff. So no description of the world can characterize the world as it is in itself. Any description must be structured, for it must exploit concepts and categories. And since the world itself is unstructured, there is bound to be some distortion when we represent it in thought and language. (1994: 56) 
It may be said that the explanation I have provided will still allow for some accurate conceptual representations of an undifferentiated reality. But, if so, these are all, or almost all, with the exception of the statement that there is a world, negative representations, that is to say, representations which specify what there is not, without specifying what there is. It seems that this explanation is therefore a better effort to present the relevant idea of an undifferentiated reality. Another difference between the explanation I have provided and the previous one is that it does not require that we think of reality as physical. The imagery used to convey the idea of an undifferentiated reality, such as a mass of undifferentiated stuff, can easily suggest a physicalist conception of it, but it is not clear that one must conceive of reality in this way in order to think of it as undifferentiated.

We have considered the reality side of the dualism, but what about the scheme side? Our conceptual scheme is said to divide up an undifferentiated reality. What does it mean to say this, though, since our concepts do not perform acts of cutting up material? There are certain norms associated with our concepts. By applying these concepts in line with the norms, we represent reality as consisting of distinct things. This is what it is for our conceptual scheme to divide up the world, or divide up reality. ('World' means reality below.) The descriptions that we ordinarily regard as uncontroversial are applications of our concepts that meet the relevant norms, or so we may suppose. But they do not succeed in identifying what there actually is. They only identify what there is from the point of view of our system of concepts, of our conceptual scheme. On the one hand, then, there is the undifferentiated world. On the other hand, there is our conceptual scheme, which provides a point of view on this world according to which it features distinct things.

The dualism of scheme and undifferentiated reality may be held along with the claim that there are others who have an alternative scheme for dividing up the world. Representations using their concepts which meet the relevant norms for applying these concepts will posit different things in the world to the things that our representations posit. The other scheme is said to divide up the world differently. But one can hold the dualism of scheme and undifferentiated reality without supposing that there are alternative schemes for dividing up the world. It might even make sense to hold this dualism while denying that there could be alternative schemes.

To explore this issue further, we would have to consider the criteria for saying that another set of concepts is an alternative scheme. I will leave this matter aside. There are other details which could be added to the exposition so far, but we are already in a position to object to the coherence of this dualism. The section below presents an objection which allows us to conclude that it is incoherent, regardless of how the details are filled in. 
3. The objection that I wish to make is a simple one, yet to my knowledge it has not appeared in the literature on this dualism. It can be introduced by considering a metaphorical way of talking which Richard Rorty finds tempting:

...people like Goodman, Putnam, and myself - people who think that there is no description-independent way the world is, no way it is under no discussion - keep being tempted to use Kantian form-matter metaphors. We are tempted to say that there were no objects before language shaped the raw material (a lot of ding-an-sichy, all-content-and-noscheme stuff). (1998: 90)

In the second sentence of this quotation, Rorty writes as if he is tempted to say that once there were no objects, then objects came into existence, after a certain event. The event, put metaphorically, is language shaping the raw material. However, I suspect that the position he regards as tempting is different to this one. The position is that there are still no distinct things, hence no objects, but if we follow certain norms for the application of our concepts, and correspondingly the words that we associate with them, the result is an account of the world as containing distinct things. This is what it is for language to shape the raw material. But if the world is undivided raw material, how can there be such a thing as our language to shape it - to divide it up in the first place?

We can formulate this objection, more precisely, as a dilemma. How can there be any conceptual schemes if the conception of reality which this dualism involves is correct? We cannot say that there are any conceptual schemes outside of reality, that is, existing without being part of reality, because it is incoherent to maintain that anything is outside of reality, whatever conception of reality we work with. But we cannot say that any conceptual schemes are part of reality either, without giving up on a conception according to which reality does not feature distinct things. If we assert that there are multiple schemes, then we suppose that they are distinct from one another. If we assert that there is only one scheme, we will surely have to maintain that this scheme is not the whole world. Thus we must allow that there is a distinction between what is the scheme and what is not. Moreover, we will have to concede that the concepts which are part of the scheme are distinct from one another.

In this paper, I will consider three different responses to this dilemma, which can be labelled the constructivist response, the Cartesian response and the Platonist response. Let us begin with the constructivist response. This response proposes that there are only conceptual schemes from the point of view of a particular conceptual scheme. Since, according to the dualists we are considering, the things that we represent as distinct items within the world are, at best, only there from the point of view of this or that scheme, it would be bewildering if an exception was made for conceptual schemes. But what is it for conceptual schemes to be there from the point of view of some scheme or other, notably our scheme? The idea is that we have a set 
of concepts which constitutes our conceptual scheme and in saying that there are conceptual schemes we are applying some of these concepts in a way that is in line with certain norms for applying them, norms that, when a statement is in line with them, it can be said to have captured some, or maybe even all, of what there is from the point of view of our scheme. The statement does not capture the world as it actually is, only as it appears to be from the point of view of our scheme. But this leads us back to the original puzzle: if the content of reality does not feature distinct things, how can there be this conceptual scheme? When we are puzzling over how there can be any schemes, asserting that there are only conceptual schemes from the point of view of our scheme is not a legitimate move. It requires that we are not faced with the puzzle when it comes to this particular scheme, but the puzzle concerns any conceptual scheme.

Let us turn now to the Cartesian response. According to this response, the claim that reality is undifferentiated need not be thought of as applying to the whole of reality. We can think of it instead as applying only to physical reality. Outside of physical reality are mental substances, minds, and this response seeks to somehow locate conceptual schemes in minds. The position which this response advocates is a departure from the position that was presented in the previous section. It would be a significant result if that position could not be sustained, if the closest one could come to doing so requires the postulation of non-material minds. But I think there is a major worry about how this alternative could ever be justified. Advocates of the dualism of scheme and undifferentiated reality typically appeal to actual or possible cases of conceptual diversity. The cases they have in mind, they think, give us reason to believe that we are introducing distinctions between things which do not correspond to how reality is (see Black 1959: 231). Our distinctions are depicted as arbitrary impositions on reality. But it seems unlikely that these cases indicate that this is so for distinctions pertaining to physical reality, while suggesting that the distinction between physical and mental reality and various distinctions concerning the latter all capture how reality is. Consequently, I doubt that any proponent of the position presented in the previous section would be attracted to this Cartesian alternative.

The final response I shall consider is the Platonist response. This response also denies that it is all of reality which is undifferentiated. But rather than distinguishing between a differentiated mental reality and an undifferentiated physical reality, it relies on a distinction between concrete and abstract reality. Concepts, one might think, are mental entities of some kind. But if that is the case, how can concepts be shared? If one person thinks that there is a tree outside and so does another, it seems that they both represent the world with the same concepts, such as the concept of a tree. But if concepts are mental entities, this does not seem possible. Rather than both using the same concepts, one person has used concepts from their mind to form their 
representation of the world, while the other person has used different concepts, concepts from that person's mind. A reason that has been given for abandoning the view that concepts are mental entities is that it has the consequence that there are no shared concepts. On the basis of this argument, it has been recommended that we think of concepts as abstract entities (see Glock 2009: 13-14). Someone who adopts this view might believe that there is a way of making sense of the claim that conceptual schemes are outside of reality. The idea is not that concepts are unreal. The idea is that concepts, like all abstract entities, are not part of concrete reality and it is this concrete reality which is undifferentiated.

Although we might be able to coherently entertain this position, once again there are concerns about whether it can be justified. The concern that I shall focus on regards justifying the claim that there are abstract concepts while conceiving of concrete reality as undifferentiated. One cannot begin, as we did above, with the premise that concepts are shared, because this conception of concrete reality does not feature people to share the concepts in the first place. I am not aware of another justification which avoids appealing to a differentiated concrete reality. This does not establish that it is impossible to justify a belief in abstract concepts while working with a conception of concrete reality as undifferentiated, but until we have seen a justification, we can leave the position under consideration aside. The Platonist response also faces much the same justificatory concern as the Cartesian response.

In this paper, I have not sought to compare the objection put forward here with previous objections to the dualism of scheme and undifferentiated reality, for instance to inquire into whether it succeeds where they fail. Regardless of what these other objections are, the objection here deserves to be known by those evaluating this dualism. This would be the case even if there was a way of defending against it, because it raises an important issue for this kind of dualist to resolve: how to make room for conceptual schemes, if reality is undifferentiated. But what I have tried to show is that there is no way of resolving this issue. 


\section{Bibliography}

Black, M. 1959. Linguistic Relativity: The Views of Benjamin Lee Whorf. Philosophical Review 68: 228-238.

Davidson, D. 1984. On the Very Idea of a Conceptual Scheme. In Inquiries into Truth and Interpretation. Oxford: Clarendon Press, 183-198.

Child, W. 1994. On the Dualism of Scheme and Content. Proceedings of the Aristotelian Society 94: 53-71.

Glock, H. 2009. Concepts: Where Subjectivism Goes Wrong. Philosophy 84: 5-29.

McDowell, J. 1999. Scheme-Content Dualism and Empiricism. In L. E. Hahn (ed.), The Philosophy of Donald Davidson. La Salle: Open Court, 87-104.

Rorty, R. 1998. Charles Taylor on Truth. In Truth and Progress: Philosophical Papers, Volume 3. Cambridge: Cambridge University Press, 84-97. 


\section{E-LOGOS}

\section{ELECTRONIC JOURNAL FOR PHILOSOPHY}

Ročník/Year: 2012 (vychází průběžně/ published continuously)

Místo vydání/Place of edition: Praha

ISSN 1211-0442

Vydává/Publisher:

Vysoká škola ekonomická v Praze / University of Economics, Prague

nám. W. Churchilla 4

Czech Republic

13067 Praha 3

IČ: 61384399

Web: http://e-logos.vse.cz

Redakce a technické informace/Editorial staff and technical information:

Miroslav Vacura

vacuram@vse.cz

Redakční rada/Board of editors:

Ladislav Benyovszky (FHS UK Praha, Czech Republic)

Ivan Blecha (FF UP Olomouc, Czech Republic)

Martin Hemelík (VŠP Jihlava, Czech Republic)

Angelo Marocco (Pontifical Athenaeum Regina Apostolorum, Rome, Italy)

Jozef Kelemen (FPF SU Opava, Czech Republic)

Daniel Kroupa (ZU Plzeň, Czech Republic)

Vladimír Kvasnička (FITT STU Bratislava, Slovak Republic)

Jaroslav Novotný (FHS UK Praha, Czech Republic)

Jakub Novotný (VŠP Jihlava, Czech Republic)

Ján Pavlík (editor-in-chief) (VŠE Praha, Czech Republic)

Karel Pstružina (VŠE Praha, Czech Republic)

Miroslav Vacura (executive editor) (VŠEE Praha, Czech Republic) 